\title{
Effect of Endoplasmic Reticular Stress on Free Hemoglobin Metabolism and Liver Injury
}

\author{
Sung-Hui Tseng ${ }^{1,2}$, Ting-Yun Chang ${ }^{3}$, Chun-Kuang Shih ${ }^{3,4}$, Rong-Hong Hsieh ${ }^{3}$, \\ Chia-Wen Chen ${ }^{3}$, Yi-Chun Chen ${ }^{3}{ }^{10}$, Mei-Hsiang Lin ${ }^{5}$ and Jung-Su Chang ${ }^{3,6, *}$ \\ 1 Department of Physical Medicine and Rehabilitation, Taipei Medical University Hospital, Taipei 110, Taiwan; \\ m003089010@tmu.edu.tw \\ 2 Department of Physical Medicine and Rehabilitation, School of Medicine, College of Medicine, Taipei \\ Medical University, Taipei 110, Taiwan \\ 3 School of Nutrition and Health Sciences, College of Nutrition, Taipei Medical University, Taipei 110, Taiwan; \\ soul0528@hotmail.com.tw (T.-Y.C.); ckshih@tmu.edu.tw (C.-K.S.); hsiehrh@tmu.edu.tw (R.-H.H.); \\ d301091008@tmu.edu.tw (C.-W.C.); yichun@tmu.edu.tw (Y.-C.C.) \\ 4 School of Food Safety, College of Nutrition, Taipei Medical University, Taipei 110, Taiwan \\ 5 Department of Pharmaceutical Science, School of Pharmacy, Taipei Medical University, Taipei 110, Taiwan; \\ mhl00001@tmu.edu.tw \\ 6 Graduate Institute of Metabolism and Obesity Sciences, College of Nutrition, Taipei Medical University, \\ Taipei 110, Taiwan \\ * Correspondence: susanchang@tmu.edu.tw; Tel.: +886-2-27361661 (ext. 6542); Fax: +886-2-27384831
}

Received: 22 May 2018; Accepted: 29 June 2018; Published: 6 July 2018

\begin{abstract}
Elevated soluble (s) CD163 and free hemoglobin (Hb) levels predict fatty liver progression; however, the molecular mechanisms underlying $\mathrm{Hb}$ metabolism and liver injury remain undefined. We investigated the effects of endoplasmic reticular (ER) stress on red blood cell (RBC) rheology and free $\mathrm{Hb}$ recycling pathways. ER stress was induced in Sprague-Dawley rats by an intraperitoneal injection of tunicamycin (TM) (50, 100, and $200 \mu \mathrm{g} / 100 \mathrm{~g}$ body weight (BW)) or an intravenous injection of $\mathrm{Hb}(5 \mathrm{mg} / 100 \mathrm{~g} \mathrm{BW})$. A TM injection increased sCD163 levels, attenuated free $\mathrm{Hb}$ uptake, and maintained RBC aggregability. An $\mathrm{Hb}$ injection increased serum LVV-hemorphin-7 and total bilirubin levels, but this effect was suppressed by TM. A Western blot analysis showed that ER stress suppressed $\mathrm{Hb}$ degradation in the liver through downregulation of globin degradation proteins cathepsin D and glyoxalase-1, as well as heme degradation protein heme oxyganase- 1 and keap-1 expression. An ER stress activator also increased the translocation of nuclear factor (NF)- $\mathrm{kB}$ (p65) and nuclear factor-erythroid 2-related factor 2 (Nrf2) to nuclei. In conclusion, ER stress triggers ineffective $\mathrm{Hb}$ metabolism via altering globin and heme iron degradation pathways. Inability to recycle and metabolize free $\mathrm{Hb}$ may underlie the association between iron dysfunction and liver injury.
\end{abstract}

Keywords: liver injury; endoplasmic reticular stress; soluble (s) CD163; free hemoglobin

\section{Introduction}

Non-alcoholic fatty liver disease (NAFLD) is the most common chronic liver disease worldwide [1]. Emerging evidence suggests that red blood cell (RBC)-CD163-hemoglobin ( $\mathrm{Hb}$ ) recycling pathways are associated with metabolic disorder such as NAFLD [2-4]. Free Hb levels in the serum predict NAFLD progression [2-4]. An elevated serum soluble (s) CD163 level is commonly observed in obese patients [5], as well as patients with metabolic disorder diseases [6-8]. Bariatric surgery [7,9] and lifestyle intervention significantly decrease sCD163 [10].

Macrophages are responsible for engulfing senescent or damaged RBCs [11,12]. Activation of $\mathrm{Hb}$-degradation pathways also triggers an important antioxidative and cytoprotective response in the 
liver [13]. RBCs are synthesized in bone marrow and have an average life span of 120 days [11,12]. Macrophages take up senescent RBCs through erythrophagocytosis in the liver and spleen. Macrophages can also scavenge free $\mathrm{Hb}$ by CD163 surface receptors [12,13]. In normal physiological conditions, the free $\mathrm{Hb}$, derived from intravascular hemolysis, is estimated to be $10-20 \%$ of the total turnover of RBCs [12]. Circulating free $\mathrm{Hb}$, a highly reactive and unstable molecule, is first bound to haptoglobin $(\mathrm{Hp})$ and then $\mathrm{Hb}-\mathrm{Hp}$ complexes are taken up by CD163+ macrophages [12]. Inside macrophages, the globin moieties of $\mathrm{Hb}$ undergo proteolytic degradation by lysosomal proteolytic enzymes (e.g., cathepsin D (CTSD)) or cytosolic enzymes (glyoxalase I (GLO-1)) [14]. Heme iron is further degraded by heme oxygenase (HO)-1, and it is stored as the less-toxic $\mathrm{Fe}^{3+}$ in ferritin. This process also generates cytoprotective effector molecules such as biliverdin and carbon monoxide (CO) $[15,16]$.

Accumulating evidence has shown that increased endoplasmic reticulmn (ER) stress-associated responses contribute to the pathophysiology of liver injury [1]. The ER is an organelle that plays a key role in nutrient metabolism. Our previous study showed that iron supplementation $(>1 \mathrm{~g}$ ferric iron $/ \mathrm{kg}$ diet) increased ER stress responses and impaired insulin signaling pathways in a rat model of streptozotocin/nicotinamide-induced diabetes [17]. ER stress-associated mechanisms are also required for ferritin-mediated macrophage [18] and hepatic stellate cell activation [19]. Vecchi et al. demonstrated that ER stress-associated mechanisms also promote anemia of inflammation (indicated by decreased serum iron and increased hepatic iron accumulation) via directly regulating the expression of the iron-regulatory hormone, hepcidin [20]. In the present study, we investigated the effects of ER stress on RBC rheology and free $\mathrm{Hb}$ degradation pathways in a rat model.

\section{Results}

\subsection{ER Stress Attenuates RBC Aggregability and Free Hb Uptake}

We performed animal studies to test whether ER stress-associated mechanisms affected RBC rheology and CD163+ macrophages mediated free $\mathrm{Hb}$ uptake and degradation. An animal study showed that a TM injection, a potent ER stress inducer through the inhibition of $N$-glycosylation, significantly decreased serum iron (Figure $1 \mathrm{~A}$ ), attenuated free $\mathrm{Hb}$ recycling in the serum (Figure 1B), and increased shedding of the CD163 surface receptor (Figure 1C) compared to control rats. Although no significant difference was observed in $\mathrm{Hb}$ levels (Figure 1D), TM reduced the release of LVV-hemorphin-7 (Figure 1E), a peptide derived from the proteolytic degradation of the $\mathrm{Hb} \beta$ chain. TM did not change RBC deformability (Figure 1F), but maintained RBC aggregability (Figure 1G).
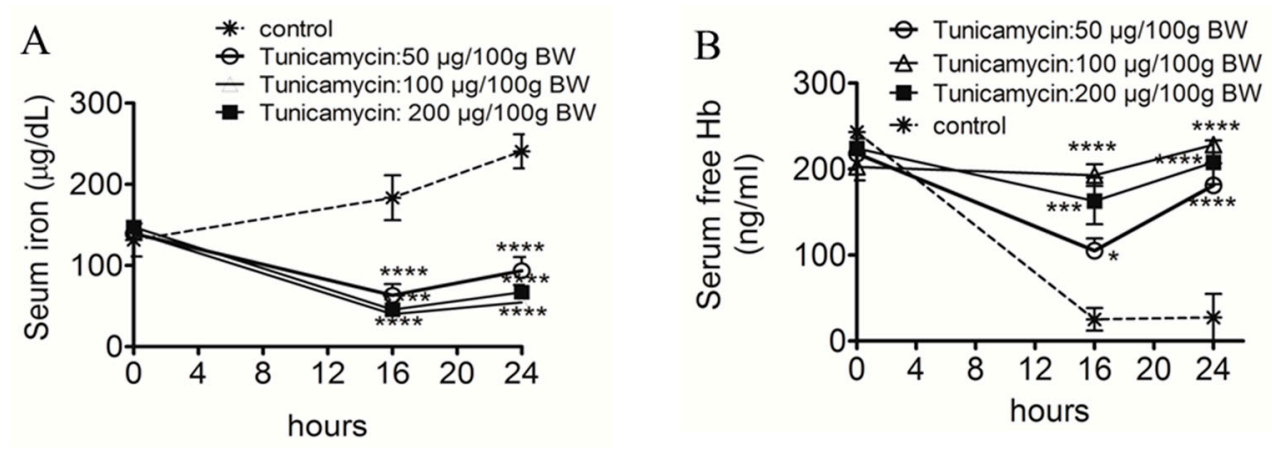

Figure 1. Cont. 
$\mathrm{C}$

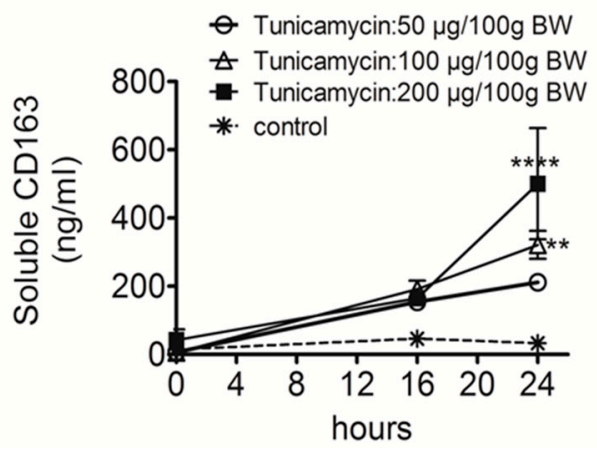

$\mathrm{E}$

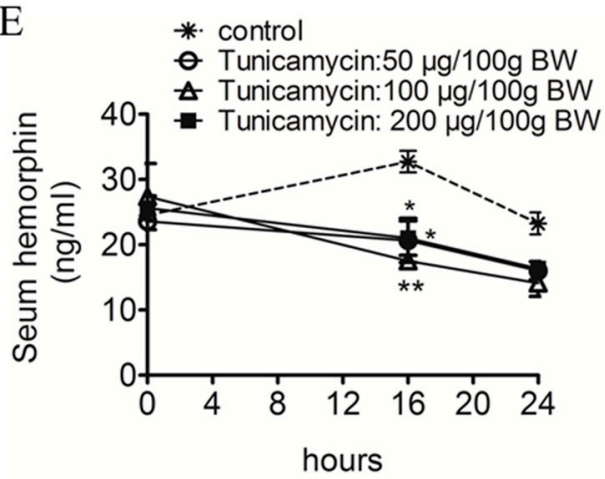

G

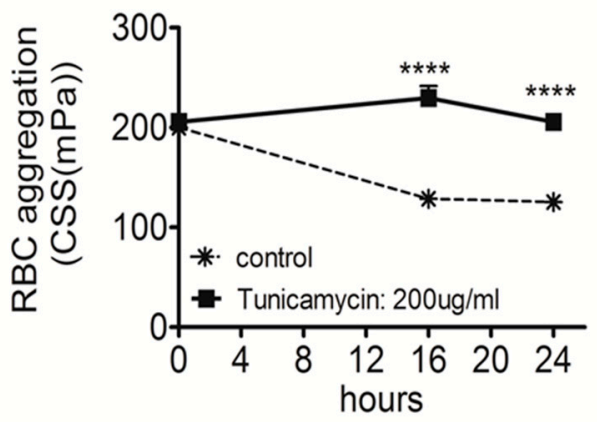

$\mathrm{D}$

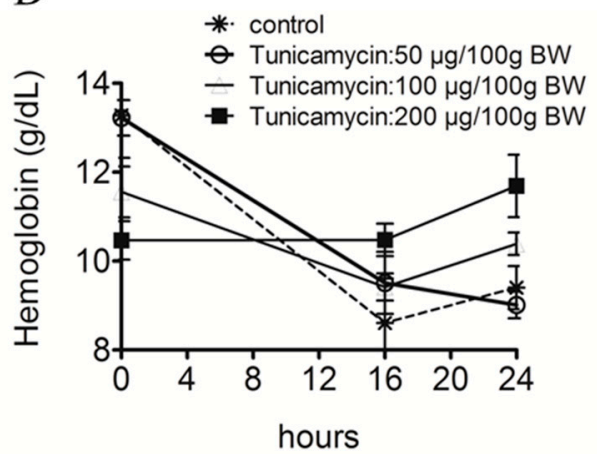

F

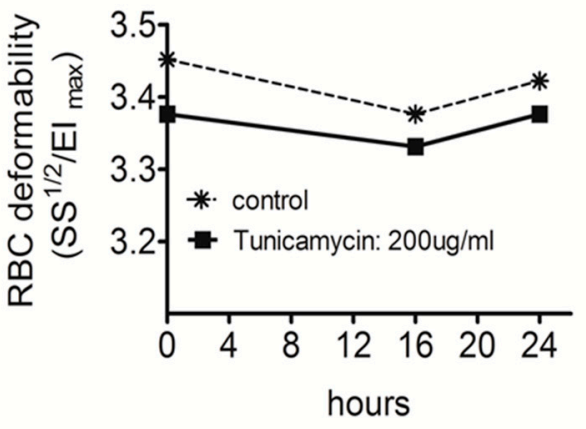

Figure 1. Effects of endoplasmic reticular stress on red blood cells, hemoglobin, and serum iron biomarkers. Rats were injected with various doses of tunicamycin (50,100, and $200 \mu \mathrm{g} / 100 \mathrm{~g}$ body weight) for $18 \mathrm{~h}$. Serum levels of iron (A), free hemoglobin (B), soluble CD163 (C), hemoglobin (D), and LVV-hemorphin-7 (E) levels were quantitated in rats. Red blood cell deformability (F) and aggregation (G) were measured by microfluidic ektacytometry. A repeated-measures analysis of variance (ANOVA) was employed for the time course analysis ( $n=4$ or 5 /group). Significant differences are indicated by ${ }^{*} p<0.05,{ }^{* *} p<0.01 ;{ }^{* * *} p<0.001$; or ${ }^{* * * *} p<0.0001$ compared to the controls at each time point.

\subsection{ER Stress Alters Hepatic Hepcidin-Ferroportin Expression}

Figure 2 shows that compared to controls, a TM $(100 \mu \mathrm{g} / 100 \mathrm{~g} \mathrm{BW})$ or TM plus $\mathrm{Hb}(5 \mathrm{mg} / 100 \mathrm{~g}$ BW) injection significantly increased hepatic Grp78 protein expression (Figure 2A,G) and free $\mathrm{Hb}$ (Figure 2B) levels in the serum. Short-term treatment with an ER stress activator did not alter $\mathrm{Hb}$ (Figure 2C) or total hepatic iron concentrations (Figure 2D). However, a Western blot analysis showed that an ER stress activator increased hepatic hepcidin (Figure 2E,G) but suppressed ferroportin protein expressions (Figure 2F,G). 


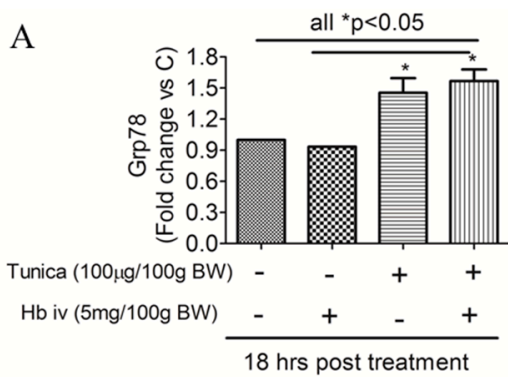

$\mathrm{C}$

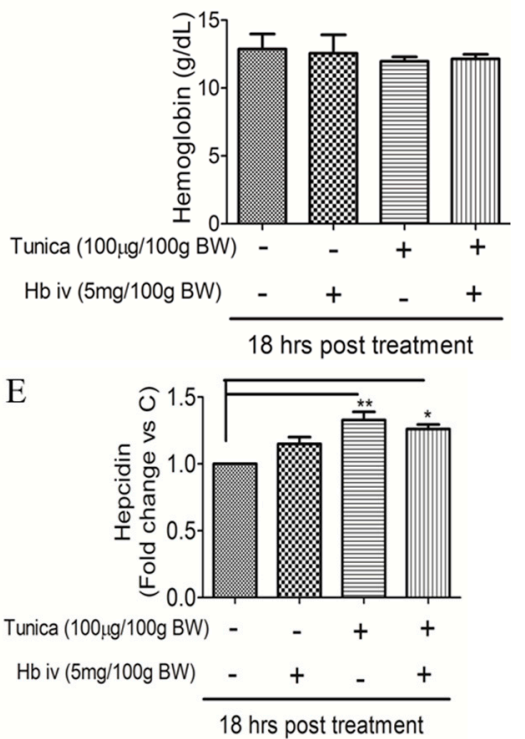

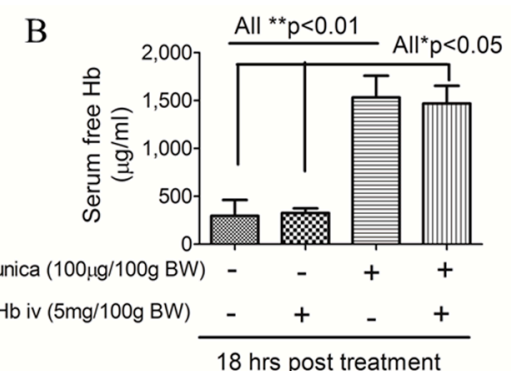

$\mathrm{D}$

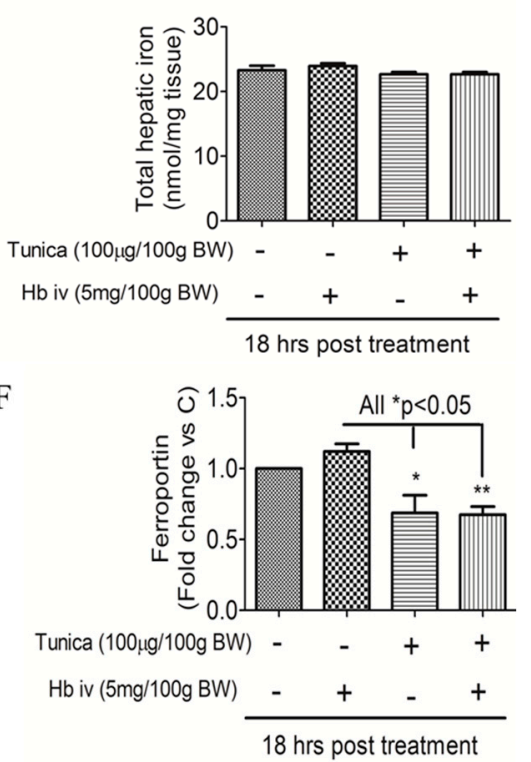

G

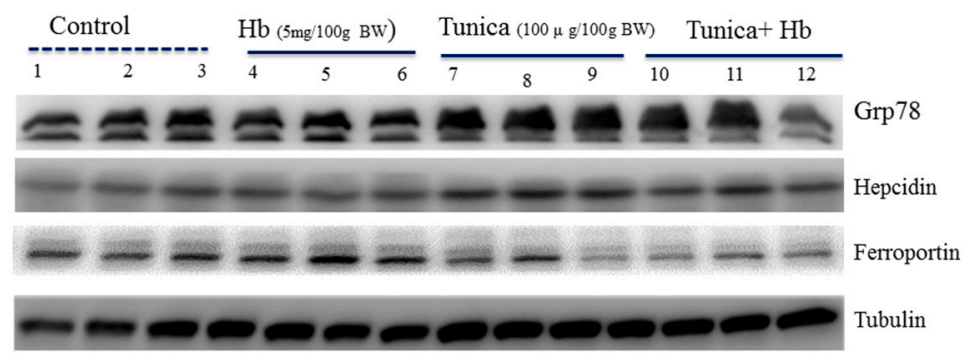

Figure 2. Effects of endoplasmic reticular stress on free hemoglobin and hepatic iron levels. Rats were injected with tunicamycin $(100 \mu \mathrm{g} / 100 \mathrm{~g}$ body weight) for $18 \mathrm{~h}$ followed by a hemoglobin $(5 \mathrm{mg} / 100 \mathrm{~g}$ body weight) injection. At $10 \mathrm{~min}$ after the hemoglobin injection, expression levels of hepatic Grp78 protein (A,G), serum free hemoglobin (B), and hemoglobin (C) were measured. Hepatic total iron levels were quantitated by an iron assay kit (D). Hepatic expressions of hepcidin (E,G) and ferroportin $(\mathbf{F}, \mathbf{G})$ were detected by a Western blot analysis. Data are expressed as the mean \pm SEM $(n=3$ per group). ${ }^{*} p<0.05 ;{ }^{* *} p<0.01$ vs. the controls or hemoglobin injection by a one-way ANOVA with the Bonferroni posttest and correction.

\subsection{ER Stress Suppresses Globin Degradation}

We next investigated how ER stress affected $\mathrm{Hb}$-degradation pathways. Figure 3 shows that, compared with controls, an $\mathrm{Hb}$ injection increased serum LVV-hemorphin-7 levels (Figure 3A) and total bilirubin levels (Figure 3B), but this effect was suppressed by TM (all $p<0.05)$. A Western blot analysis showed that $\mathrm{Hb}$ or TM injection triggered hepatic CD163 protein expression (Figure $3 \mathrm{C}, \mathrm{G}$ ). $\mathrm{An} \mathrm{Hb}$ injection also slightly increased serum ADAM17 levels, a metalloproteinase which is known 
to cleave the full-length CD163 receptor, but an ER stress activator reversed this effect (Figure 3D). The ER stress activator also suppressed Hb degradation proteins (CTSD and GLO1) (Figure 3E-G).

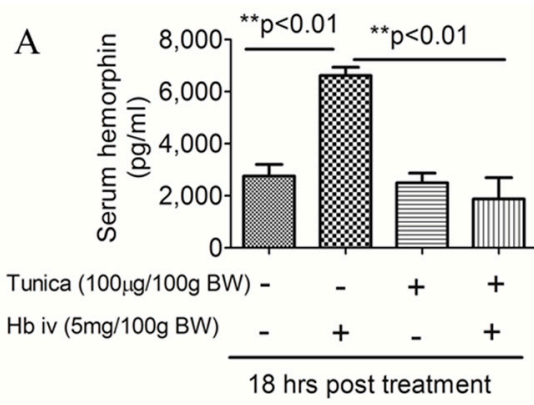

C

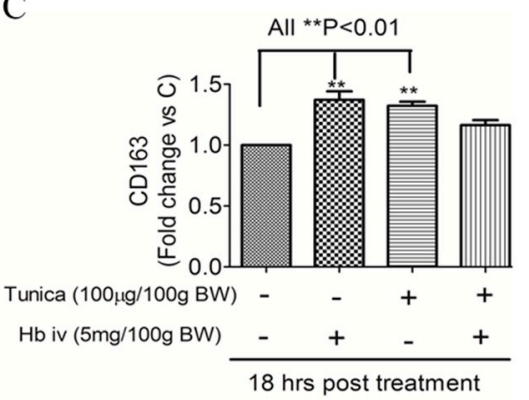

E

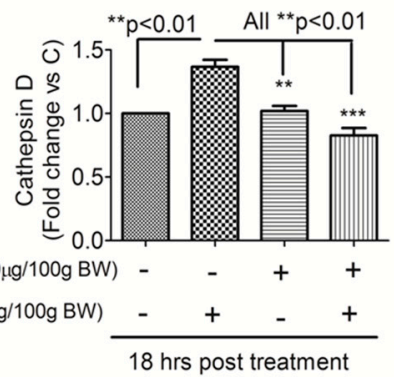

G

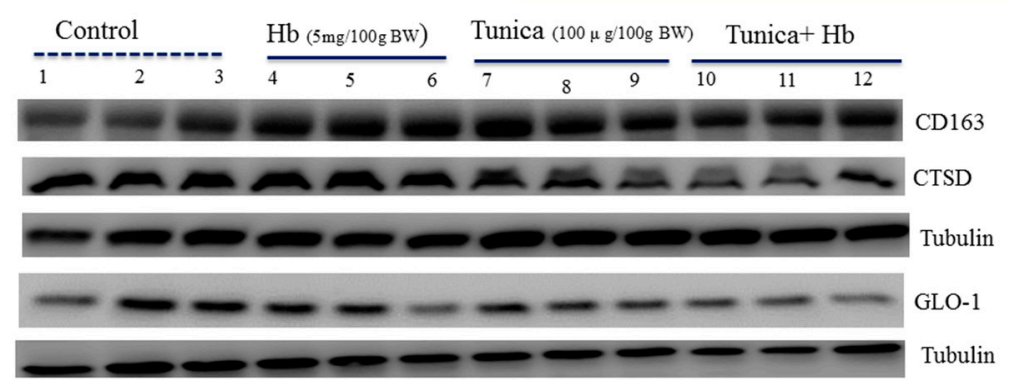

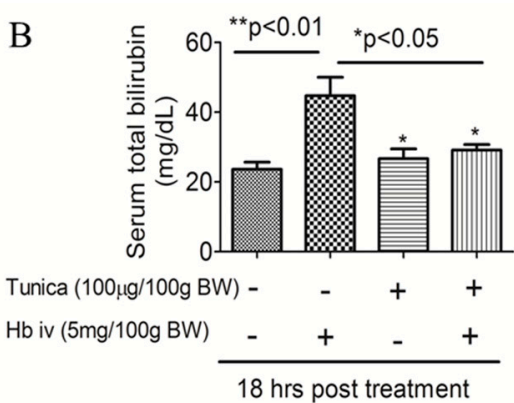

D

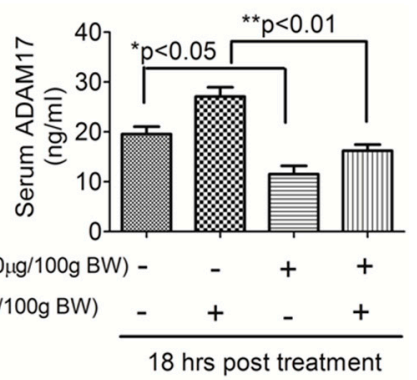

F

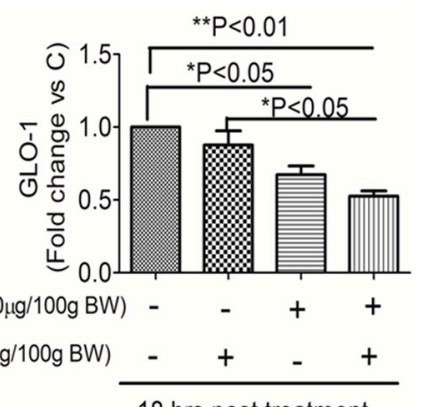

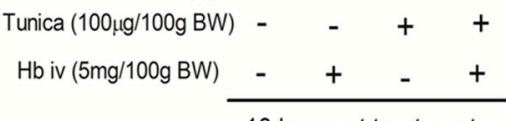

18 hrs post treatment

Figure 3. Effects of endoplasmic reticular (ER) stress on hemoglobin degradation protein expressions in the serum and livers of rats. Serum LVV-hemorphin-7 (A), total bilirubin (B), and ADAM17 levels were measured (D). Hepatic expressions of hemoglobin uptake and degradation proteins of CD163 (C,G), cathepsin D (CTSD) (E,G), and glyoxalase-1 (GLO-1) $(\mathbf{F}, \mathrm{G})$ were detected by a Western blot analysis (C,D). Data are expressed as the mean $\pm \operatorname{SEM}\left(n=3\right.$ per group). ${ }^{*} p<0.05 ;{ }^{* *} p<0.01$; or ${ }^{* * *} p<0.001$ vs. the controls or hemoglobin injection by a one-way ANOVA with the Bonferroni posttest and correction.

\subsection{ER Stress Alters Heme Iron Degradation via Increasing Heme Oxygesnase-1 Trafficking}

Figure 4 shows that an $\mathrm{Hb}$ injection increased the HO- 1 complete form (Figure 4A,I) and keap-1 expression (Figure $4 \mathrm{C}, \mathrm{I}$ ), but this effect was suppressed by TM. In contrast, the ER stress activator increased truncated HO-1 expression (Figure 4B,G), and the translocation of Nrf-2 (Figure 4D,I) and 
NF- $\mathrm{BB}$ (p65) (Figure 4E,I) to nuclei but not cleaved-caspase-3 (Figure 4I). The TM injection increased hepatic NO levels, but this did not reach statistical significance (Figure 4F). There was significant elevation in serum AST levels in rats that received a TM plus $\mathrm{Hb}$ injection when compared with controls (Figure 4G). No statistically significant difference was observed in serum ALT levels among groups (Figure $4 \mathrm{H}$ ).

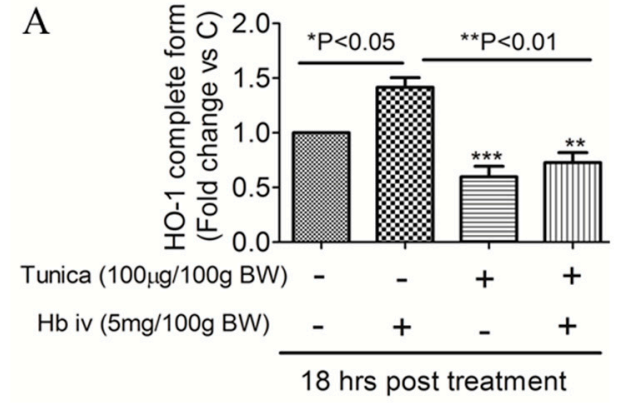

$\mathrm{C}$
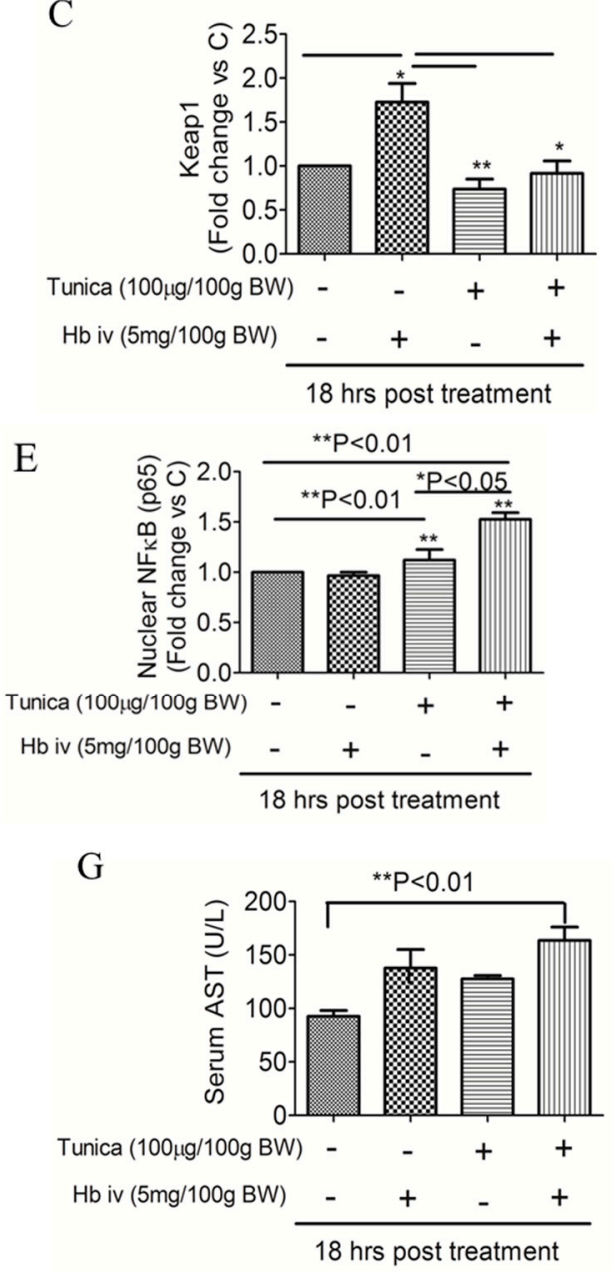

B

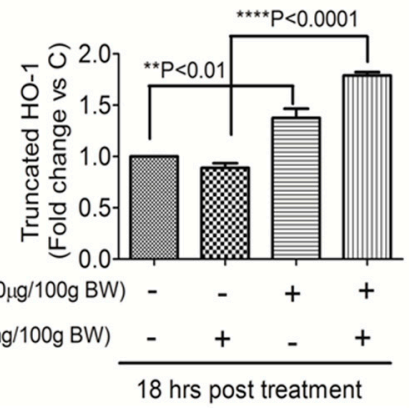

$\mathrm{D}$

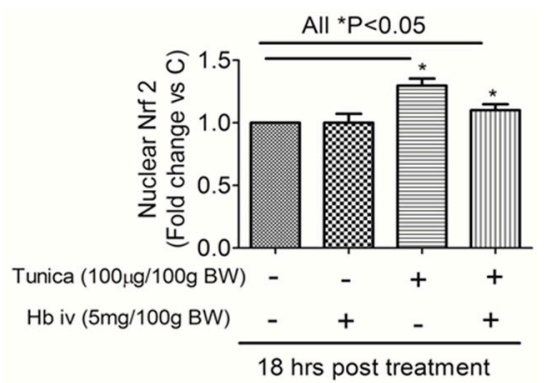

F

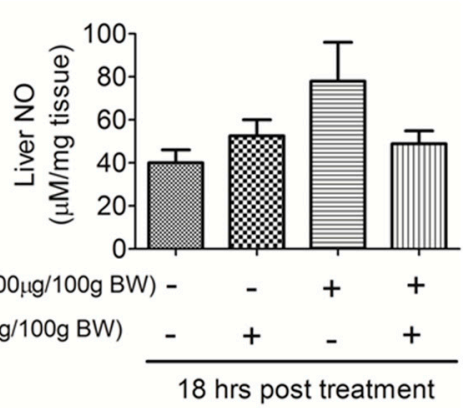

$\mathrm{H}$

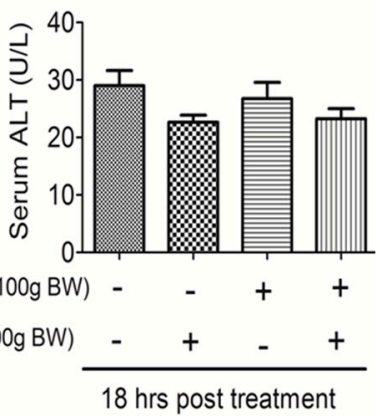

Figure 4. Cont . 
I

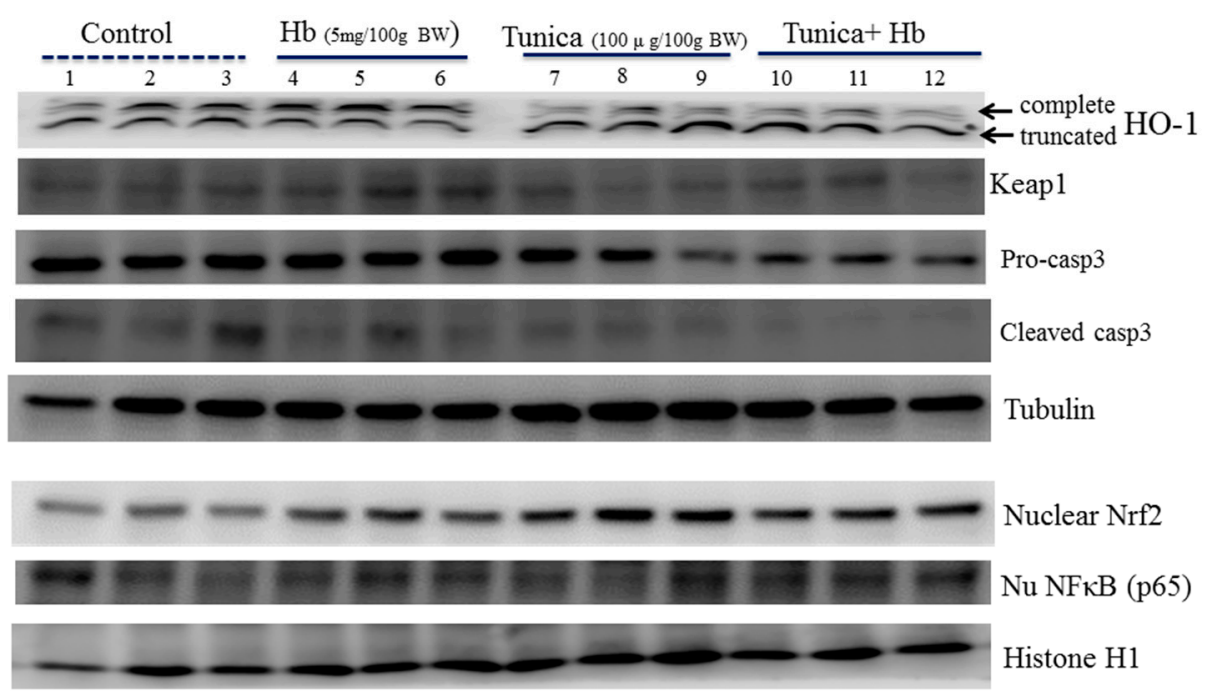

Figure 4. Effects of endoplasmic reticular stress on heme oxygenase (HO)-1, nuclear factor-erythroid 2-related factor 2 (NHrf2), and nuclear factor (NF)- $\mathrm{kB}$ (p65) protein expressions in the livers of rats. Expressions of the HO-1 complete form (A,I) and truncated form (B,I), Keap-1 (C,I), nuclear Nrf2 $(\mathbf{D}, \mathbf{I})$, and NF-kB p65 subunits (E,I) were detected by a Western blot analysis. Hepatic nitrite was detected by the Griess reagent system (F). Serum AST (G) and ALT (H) levels were measured using a colorimetric method. Data are expressed as the mean $\pm \operatorname{SEM}\left(n=3-4\right.$ per group). ${ }^{*} p<0.05 ;{ }^{* *} p<0.01$; or ${ }^{* * *} p<0.001$; or ${ }^{* * * *} p<0.0001$ vs. the controls or hemoglobin injection by a one-way ANOVA with the Bonferroni posttest and correction.

\section{Discussion}

Liver is the primary organ for iron storage and iron dysfunction can cause liver damage. Our study agrees with Vecchi and colleague's observation in which that ER stress impairs intracellular iron efflux via altering hepatic hepcidin-ferroportin expression levels [20]. Our study further demonstrated that ER stress-associated mechanisms also affected RBC aggregability and free $\mathrm{Hb}$ uptake and degradation. The attenuation of free $\mathrm{Hb}$ recycling is likely due to increased shedding of the full-length CD163 receptor on macrophages via ADAM-17-independent pathways. In addition, ER stress responses impair hepatic $\mathrm{Hb}$ metabolism through down-regulation of (1) globin degradation (indicated by decreased circulating hemorprotein and globin-degradation proteins CTSD and GLO-1) and (2) heme iron degradation (indicated by decreased keap-1 and HO-1 complete form). Therefore, an inability to recycle and metabolize free $\mathrm{Hb}$ may promote liver injury due to the molecular instability of free heme iron, as well as decreased levels of $\mathrm{Hb}$-derived bioactive peptides and byproducts (e.g., LVV-hemorphin-7 and bilirubin).

The sCD163 molecule is regarded as a macrophage activation marker or an acute-phase reactant. Currently, the pathophysiological role of elevated SCD163 in liver injury remains largely unknown. TNF- $\alpha$-cleaving enzyme (TACE)/ADAM17 and neutrophil elastase are known to cleave surface CD163 receptors on monocytes and macrophages [21,22]. Etzerodt et al. showed that although sCD163 is detectable in mouse serum, shedding of the CD163 receptor in mice is ADAM17-independent [22,23]. Our data agree with this notion. We found that a TM injection increased serum sCD163 levels, but no difference was found in serum ADAM17 levels. This suggests that similar to mice, shedding of the CD163 receptor in rats is independent of ADAM-17. Those authors also suggested that unlike humans, mouse $\mathrm{Hb}$ does not have a high affinity for $\mathrm{Hp}$, but binds with high affinity to CD163 [23]. This indicates that the clearance of free $\mathrm{Hb}$ may vary depending on the animal species. Nonetheless, our clinical study found that serum sCD163 and free $\mathrm{Hb}$ levels were closely associated with fatty liver 
severity (JS Chang preliminary data). This suggests that under inflammatory conditions or exposure to ER stress, increased shedding of the CD163 receptor may downregulate macrophages' ability to scavenge free $\mathrm{Hb}$.

After macrophages take up senescent $\mathrm{RBC}$ s or free $\mathrm{Hb}$, lysosomal proteolytic enzymes degrade the globin moieties to produce various bioactive peptides [14]. Hemorphins are short peptides derived from the $\mathrm{N}$-terminal region of the $\beta$-globin chain that shares a central tetrapeptide core of Tyr-Pro-Trp-Thr [24]. LVV-hemorphin-7, a ten-residue peptide, can decrease blood pressure through inhibiting angiotensin-converting enzymes [25]. LVV-hemorphin-7 also plays important roles in learning and memory $[25,26]$. Clinical studies showed that serum LVV hemorphin-7 levels were lower in patients with obesity and type 2 diabetes compared to controls $[27,28]$. Our study showed that an $\mathrm{Hb}$ injection increased serum LVV-hemorphin-7 and total bilirubin levels, but this effect was suppressed by the TM injection. This suggests that hemoprotein degradation is also subjected to ER stress.

Our study demonstrated that ER stress may control heme iron degradation via regulating HO-1 trafficking, the key enzyme involved in heme degradation. HO-1 is a smooth ER-anchored protein that faces the cytosol [29]. When heme is released from hemoprotein, HO-1 couples with cytochrome p450 reductase to degrade heme iron into ferrous iron and generate bilirubin and $\mathrm{CO}$ as byproducts. However, Lin and colleagues indicated an alternative role of HO-1 [30]. Lin et al. first reported the translocation of HO-1 to nuclei, and nuclear HO-1 may activate genes that promote cytoprotection against oxidative stress [30]. Further study demonstrated that nuclear HO-1 partners with Nrf2, and the HO-1-Nrf2 interaction triggers antioxidative stress responses [31]. Our study showed that an $\mathrm{Hb}$ injection increased expressions of the HO-1 complete form and keap-1, but this effect was suppressed by TM. In contrast, an ER stress activator increased truncated HO-1 expression and translocation of Nrf-2 and NF-kB (p65) to nuclei. This suggests that under ER stress conditions, HO-1 and Nrf-2 may be translocated to nuclei to alleviate oxidative stress. Nuclear HO-1-Nrf-2 is also known to activate ferroportin expression, which may help release recycled iron to peripheral areas and prevent tissue iron accumulation. Our data showed that TM increased nuclear Nrf-2 but decreased ferroportin, suggesting that Nrf-2-independent pathways may be involved in downregulating ferroportin. Our study also raised the possibility that increased HO-1 isoforms may impair the HO-1 enzymatic ability to convert heme iron under ER stress.

There are several commercially available pharmaceutical ER stress inducers including tunicamycin and thapsigargin and brefedin A [32]. Brefedin A inhibits the transport of protein from the ER to Golgi apparatus and this leads to the accumulation of unfolded protein in the ER. Thapsigargin, an inhibitor of sarco/ER Ca ${ }^{2+}$ ATPase, decreases calcium levels and affects the activity of calcium-dependent chaperone in ER. Tunicamycin is an inhibitor of N-linked glycoprotein biosynthesis in the ER. ER stress activators cause misfolded and unfolded protein to become accumulated in the lumen of ER, leading to the activation of the unfolded protein response (UPR) or ER stress response [32]. Our study used tunicamycin to induce ER stress because N-linked glycosylation is known to affect iron acquisition protein (e.g., transferrin, transferrin receptor 2) and iron storage protein (e.g., ferritin) [33,34]. Glycosylation may also affect the iron binding capacity of transferrin and ferritin as alterations in the protein structure may affect protein stability and immunogenicity [34].

ER stress can be induced within a few hours after treatment with ER stress inducers and a longer exposure time tends to trigger cell death [32]. Our study showed that $18 \mathrm{~h}$ treatment of tunicamycin or tunicamycin plus $\mathrm{Hb}$ injection did not cause elevation in levels of serum ALT, hepatic NO, and pro-and cleaved caspase 3 protein. This suggests that the liver is able to recover from acute ER stress and a longer treatment time may be necessary to see the tunicamysin-mediated liver injury or cell death. Another possibility is that caspase-3 may not be sensitive enough to reflect ER-tress mediated apoptosis. The literature shows that ER stress mediated cell death is C/EBP homologous protein (CHOP) dependent [35]. The dissociation of ER-resident chaperone Grp78 from the membrane anchored receptors ATF6, IRE1, and PERK triggers three UPR signal transduction pathways: ATF6, IRE1-XBP1, and PERK-eIF2 $\alpha$-ATF4. Activation of the PERK-eIF2 $\alpha$ pathway attenuates global protein 
translation, but it also leads to a selective translation such as apoptotic genes (e.g., CHOP, ATF4) and anti-oxidative genes (e.g., Nrf2) [36]. Our study did not measure CHOP due to budget restraints. The present study also found that TM plus $\mathrm{Hb}$ injection significantly induced serum AST levels. Serum AST and ALT levels are biomarkers of hepatocellular injury which are released into the blood by the damaged hepatocyte. The ALT enzyme is secreted predominantly in the liver, whilst the AST enzyme can be derived from various organs including the liver, skeletal muscle, kidney, and heart. Collectively, the present results seem to suggest that the UPR is able to alleviate the acute ER stress induced by the short-term exposure of tunicamycin or tunicamycin plus $\mathrm{Hb}$ injection. However, $18 \mathrm{~h}$ treatment of tunicamycin plus $\mathrm{Hb}$ injection may also cause cell death in other organs (e.g., skeletal muscle), as indicated by the increased levels of serum AST.

\section{Materials and Methods}

\subsection{Rat Experiment}

Thirty-Two male Sprague-Dawley (SD) rats aged 10 weeks (374.2 $\pm 20.0 \mathrm{~g})$ were purchased from BioLasco (Taipei, Taiwan) and kept under standard conditions at the animal facility of Taipei Medical University. The reason that only adult male SD rats were used was to minimize the effects of growth or sex hormone (e.g., estradiol) and menstrual cycle on iron status [37]. The experimental protocol was approved by the Animal Ethical Committee of Taipei Medical University (LAC-2015-0201; (15, $12,2015)$ ). Tunicamycin (TM) is an inhibitor of $N$-glycosylation and a potent ER stress inducer. For the TM titration experiment ( $n=4$ or 5 rats per group), SD rats were given an intraperitoneal (IP) injection of various doses of TM (50, 100, and $200 \mu \mathrm{g} / 100 \mathrm{~g}$ body weight (BW)) or vehicle (5\% DMSO) to induce acute ER stress. Blood was taken at 0,16 , and $24 \mathrm{~h}$ post-injection. In the second experiment, $\mathrm{TM}(100 \mu \mathrm{g} / 100 \mathrm{~g} \mathrm{BW})$ was IP-injected into rats at $18 \mathrm{~h}$ prior to an intravenous (IV) $\mathrm{Hb}$ injection ( $5 \mathrm{mg} /$ $100 \mathrm{~g} \mathrm{BW}$ ) (all purchased from Sigma-Aldrich, St. Louis, MO, USA). Rats were killed at 15 min after the $\mathrm{Hb}$ injection.

\subsection{Blood Biochemistry}

Fasting blood samples were collected and separated into RBCs, serum, and plasma. Samples were stored at $-80^{\circ} \mathrm{C}$ until being analyzed. RBC deformability and aggregation were measured by a microfluidic ektacytometer (RheoScan-AnD 300, RheoMeditech, Seoul, Korea). RBC rheology was defined as either the critical shear stress (CSS) or shear stress required for one-half maximal elongation $\left(\mathrm{SS}^{1 / 2}\right)$. Greater CSS values reflect higher RBC aggregability [38], and higher $\mathrm{SS}^{1 / 2}$ values indicate a decrease in RBC deformability [39]. Free Hb (ICL; Mountainside, NJ, USA) and soluble CD163 (R\&D Systems, Shanghai, China) levels in serum were determined by enzyme-linked immunosorbent assay (ELISA) kits, according to the manufacturer's instructions. Hb levels were assessed by a colorimetric method (Fortress Diagnostics, Northern Ireland, UK). Serum total bilirubin was quantitated with a Bilirubin Assay Kit (Cell Biolabs, San Diego, CA, USA) based on the Jendrassik-Frof method. Serum and liver total iron (40 mg liver sample/test) were quantitated by an iron assay kit (Abcam, Cambridge, UK) according to the manufacturer's instructions. Serum levels of aspartate aminotransferase (AST) and alanine aminotransferease (ALT) were measured using a colorimetric method by the Beckman DxC 800 (Beckman Coulter, Brea, CA, USA).

\subsection{Western Blot Analysis}

Total protein was extracted from whole-liver tissues as previously described [17]. Briefly, $50 \mathrm{mg}$ of tissues was lysed in RIPA buffer, and the protein concentration was determined with a Pierce ${ }^{\mathrm{TM}} \mathrm{BCA}$ Protein Assay Kit (Thermo Fisher Scientific, Waltham, MA, USA). Nuclear and cytosolic fractions were separated from the liver lysates using an NE-PER Nuclear and Cytoplasmic Extraction kit (Thermo Fisher Scientific, Taipei, Taiwan). The nuclear Nrf2 and NFאB (p65) were normalized against Histone H1 (Figure 4G). Anti-rat antibodies (Abs) for tubulin, histone, CTSD, GLO-1, GRP78, hepcidin, ferroportin 
(FPN), nuclear factor (erythroid-derived 2)-like 2 (Nrf2), keap1, CD163, HO-1, caspase-3, and nuclear factor $(N F)-\kappa B$ (p65) were used at dilutions of 1:1000 or 1:2000 to detect immunoreactive signals. Antibodies were purchased from Santa Cruz Biotechnology (Dallas, TX, USA), except for Grp78 (Cell Signaling, Danvers, MA, USA), GLO-1 (Abcam, Cambridge, UK), CTSD (Sigma-Aldrich, St. Louis, MO, USA), histone H1, caspase-3 (GeneTex, Irvine, CA, USA), and HO-1 (Enzo Life Sciences, Lausen, Switzerland).

\subsection{Statistical Analysis}

Statistical analyses were performed using GraphPad Prism 5 (La Jolla, CA, USA). A repeatedmeasures analysis of variance (ANOVA) was employed for the time course analysis. The trend test was analyzed by a general linear model for continuous variables. A one-way ANOVA with the Bonferroni posttest and correction was used to examine the means of more than two groups. Data are presented as the mean \pm standard error of the mean (SEM). $p<0.05$ was considered statistically significant.

\section{Conclusions}

Successful $\mathrm{Hb}$ metabolism not only protects cells against free $\mathrm{Hb}$-mediated toxicity, but $\mathrm{Hb}$ degradation byproducts (e.g., LVV-hemorphin-7, CO, and biliverdin) also exert important anti-inflammatory effects [14]. Regulation of $\mathrm{Hb}$ metabolism by ER stress further strengthens the important role of ER stress in controlling iron metabolism under conditions of cellular stress.

Author Contributions: S.-H.T. and J.-S.C. conceived and designed the experiments; T.-Y.C. performed the experiments; T.-Y.C. and C.-K.S. analyzed the data; S.-H.T., R.-H.H., M.-H.L., C.-W.C., and Y.-C.C. contributed reagents/materials/analysis tools; J.-S.C. wrote the paper.

Funding: Jung-Su Chang was supported by grants from Taipei Medical University Hospital (107TMU-TMUH-11) and the Ministry of Science and Technology, Taiwan (106-2320-B-038-034).

Conflicts of Interest: The authors declare no conflict of interest.

\section{References}

1. Pagliassotti, M.J. Endoplasmic reticulum stress in nonalcoholic fatty liver disease. Annu. Rev. Nutr. 2012, 32, 17-33. [CrossRef] [PubMed]

2. Trak-Smayra, V.; Dargere, D.; Noun, R.; Albuquerque, M.; Yaghi, C.; Gannage-Yared, M.H.; Bedossa, P.; Paradis, V. Serum proteomic profiling of obese patients: Correlation with liver pathology and evolution after bariatric surgery. Gut 2009, 58, 825-832. [CrossRef] [PubMed]

3. Yilmaz, Y.; Senates, E.; Ayyildiz, T.; Colak, Y.; Tuncer, I.; Ovunc, A.O.; Dolar, E.; Kalayci, C. Characterization of nonalcoholic fatty liver disease unrelated to the metabolic syndrome. Eur. J. Clin. Investig. 2012, 42, 411-418. [CrossRef] [PubMed]

4. Yu, C.; Xu, C.; Xu, L.; Yu, J.; Miao, M.; Li, Y. Serum proteomic analysis revealed diagnostic value of hemoglobin for nonalcoholic fatty liver disease. J. Hepatol. 2012, 56, 241-247. [CrossRef] [PubMed]

5. Fjeldborg, K.; Christiansen, T.; Bennetzen, M.; H, J.M.; Pedersen, S.B.; Richelsen, B. The macrophage-specific serum marker, soluble cd163, is increased in obesity and reduced after dietary-induced weight loss. Obesity 2013, 21, 2437-2443. [CrossRef] [PubMed]

6. Kazankov, K.; Barrera, F.; Moller, H.J.; Rosso, C.; Bugianesi, E.; David, E.; Ibrahim Kamal Jouness, R.; Esmaili, S.; Eslam, M.; McLeod, D.; et al. The macrophage activation marker scd163 is associated with morphological disease stages in patients with non-alcoholic fatty liver disease. Liver Int. 2016, 36, 1549-1557. [CrossRef] [PubMed]

7. Kazankov, K.; Moller, H.J.; Lange, A.; Birkebaek, N.H.; Holland-Fischer, P.; Solvig, J.; Horlyck, A.; Kristensen, K.; Rittig, S.; Handberg, A.; et al. The macrophage activation marker scd163 is associated with changes in nafld and metabolic profile during lifestyle intervention in obese children. Pediatr. Obes. 2015, 10, 226-233. [CrossRef] [PubMed]

8. Mueller, J.L.; Feeney, E.R.; Zheng, H.; Misdraji, J.; Kruger, A.J.; Alatrakchi, N.; King, L.Y.; Gelrud, L.; Corey, K.E.; Chung, R.T. Circulating soluble cd163 is associated with steatohepatitis and advanced fibrosis in nonalcoholic fatty liver disease. Clin. Transl. Gastroenterol. 2015, 6, e114. [CrossRef] [PubMed] 
9. Kazankov, K.; Tordjman, J.; Moller, H.J.; Vilstrup, H.; Poitou, C.; Bedossa, P.; Bouillot, J.L.; Clement, K.; Gronbaek, H. Macrophage activation marker soluble cd163 and non-alcoholic fatty liver disease in morbidly obese patients undergoing bariatric surgery. J. Gastroenterol. Hepatology. 2015, 30, 1293-1300. [CrossRef] [PubMed]

10. Rodgaard-Hansen, S.; St George, A.; Kazankov, K.; Bauman, A.; George, J.; Gronbaek, H.; Jon Moller, H. Effects of lifestyle intervention on soluble cd163, a macrophage activation marker, in patients with non-alcoholic fatty liver disease. Scand. J. Clin. Lab. Investig. 2017, 77, 498-504. [CrossRef] [PubMed]

11. Ganz, T. Macrophages and systemic iron homeostasis. J. Innate Immun. 2012, 4, 446-453. [CrossRef] [PubMed]

12. Thomsen, J.H.; Etzerodt, A.; Svendsen, P.; Moestrup, S.K. The haptoglobin-cd163-heme oxygenase-1 pathway for hemoglobin scavenging. Oxid. Med. Cell. Longev. 2013, 2013, 523652. [CrossRef] [PubMed]

13. Schaer, C.A.; Schoedon, G.; Imhof, A.; Kurrer, M.O.; Schaer, D.J. Constitutive endocytosis of cd163 mediates hemoglobin-heme uptake and determines the noninflammatory and protective transcriptional response of macrophages to hemoglobin. Circ. Res. 2006, 99, 943-950. [CrossRef] [PubMed]

14. Gomes, I.; Dale, C.S.; Casten, K.; Geigner, M.A.; Gozzo, F.C.; Ferro, E.S.; Heimann, A.S.; Devi, L.A. Hemoglobin-derived peptides as novel type of bioactive signaling molecules. AAPS J. 2010, 12, 658-669. [CrossRef] [PubMed]

15. Fruitier, I.; Garreau, I.; Lacroix, A.; Cupo, A.; Piot, J.M. Proteolytic degradation of hemoglobin by endogenous lysosomal proteases gives rise to bioactive peptides: Hemorphins. FEBS Lett. 1999, 447, 81-86. [CrossRef]

16. Nielsen, M.J.; Moestrup, S.K. Receptor targeting of hemoglobin mediated by the haptoglobins: Roles beyond heme scavenging. Blood 2009, 114, 764-771. [CrossRef] [PubMed]

17. Liu, K.L.; Chen, P.Y.; Wang, C.M.; Chen, W.Y.; Chen, C.W.; Owaga, E.; Chang, J.S. Dose-related effects of ferric citrate supplementation on endoplasmic reticular stress responses and insulin signalling pathways in streptozotocin-nicotinamide-induced diabetes. Food Funct. 2016, 7, 194-201. [CrossRef] [PubMed]

18. Wang, C.-M.; Chen, Y.-H.; Lee, Y.-C.; Chang, J.-S. Endoplasmic reticulum stress contributes to ferritin molecules-mediated macrophage migration via P-selectin glycoprotein ligand-1. Mol. Nutr. Food Res. 2017. [CrossRef] [PubMed]

19. Wang, C.M.; Li, S.J.; Wu, C.H.; Hu, C.M.; Cheng, H.W.; Chang, J.S. Transient knock down of grp78 reveals roles in serum ferritin mediated pro-inflammatory cytokine secretion in rat primary activated hepatic stellate cells. Asian Pac. J. Cancer Prev. 2014, 15, 605-610. [CrossRef] [PubMed]

20. Vecchi, C.; Montosi, G.; Zhang, K.; Lamberti, I.; Duncan, S.A.; Kaufman, R.J.; Pietrangelo, A. Er stress controls iron metabolism through induction of hepcidin. Science 2009, 325, 877-880. [CrossRef] [PubMed]

21. Etzerodt, A.; Maniecki, M.B.; Moller, K.; Moller, H.J.; Moestrup, S.K. Tumor necrosis factor alpha-converting enzyme (tace/adam17) mediates ectodomain shedding of the scavenger receptor cd163. J. Leukoc. Biol. 2010, 88, 1201-1205. [CrossRef] [PubMed]

22. Etzerodt, A.; Rasmussen, M.R.; Svendsen, P.; Chalaris, A.; Schwarz, J.; Galea, I.; Moller, H.J.; Moestrup, S.K. Structural basis for inflammation-driven shedding of cd163 ectodomain and tumor necrosis factor- $\alpha$ in macrophages. J. Biol. Chem. 2014, 289, 778-788. [CrossRef] [PubMed]

23. Etzerodt, A.; Kjolby, M.; Nielsen, M.J.; Maniecki, M.; Svendsen, P.; Moestrup, S.K. Plasma clearance of hemoglobin and haptoglobin in mice and effect of cd163 gene targeting disruption. Antioxid. Redox Signal. 2013, 18, 2254-2263. [CrossRef] [PubMed]

24. Nyberg, F.; Sanderson, K.; Glamsta, E.L. The hemorphins: A new class of opioid peptides derived from the blood protein hemoglobin. Biopolymers 1997, 43, 147-156. [CrossRef]

25. Fruitier-Arnaudin, I.; Cohen, M.; Bordenave, S.; Sannier, F.; Piot, J.M. Comparative effects of angiotensin iv and two hemorphins on angiotensin-converting enzyme activity. Peptides 2002, 23, 1465-1470. [CrossRef]

26. Lee, J.; Albiston, A.L.; Allen, A.M.; Mendelsohn, F.A.; Ping, S.E.; Barrett, G.L.; Murphy, M.; Morris, M.J.; McDowall, S.G.; Chai, S.Y. Effect of i.C.V. Injection of at4 receptor ligands, nle1-angiotensin iv and lvv-hemorphin 7, on spatial learning in rats. Neuroscience 2004, 124, 341-349. [CrossRef] [PubMed]

27. Fruiter, A., II; Cohen, M.M.; Nervi, S.S.; Bordenave, S.S.; Sannier, F.F.; Piot, J.M. Reduced level of opioid peptides, hemorphin-7 peptides, in serum of diabetic patients. Diabetes Care 2003, 26, 2480. [CrossRef]

28. Maraninchi, M.; Feron, D.; Fruitier-Arnaudin, I.; Begu-Le Corroller, A.; Nogueira, J.P.; Mancini, J.; Valero, R.; Piot, J.M.; Vialettes, B. Serum hemorphin-7 levels are decreased in obesity. Obesity 2013, 21, 378-381. [CrossRef] [PubMed] 
29. Gottlieb, Y.; Truman, M.; Cohen, L.A.; Leichtmann-Bardoogo, Y.; Meyron-Holtz, E.G. Endoplasmic reticulum anchored heme-oxygenase 1 faces the cytosol. Haematologica 2012, 97, 1489-1493. [CrossRef] [PubMed]

30. Lin, Q.; Weis, S.; Yang, G.; Weng, Y.H.; Helston, R.; Rish, K.; Smith, A.; Bordner, J.; Polte, T.; Gaunitz, F.; et al. Heme oxygenase- 1 protein localizes to the nucleus and activates transcription factors important in oxidative stress. J. Biol. Chem. 2007, 282, 20621-20633. [CrossRef] [PubMed]

31. Biswas, C.; Shah, N.; Muthu, M.; La, P.; Fernando, A.P.; Sengupta, S.; Yang, G.; Dennery, P.A. Nuclear heme oxygenase-1 (ho-1) modulates subcellular distribution and activation of nrf2, impacting metabolic and anti-oxidant defenses. J. Biol. Chem. 2014, 289, 26882-26894. [CrossRef] [PubMed]

32. Oslowski, C.M.; Urano, F. Measuring er stress and the unfolded protein response using mammalian tissue culture system. Methods Enzymol. 2011, 490, 71-92. [PubMed]

33. Zhao, N.; Enns, C.A. N-linked glycosylation is required for transferrin-induced stabilization of transferrin receptor 2, but not for transferrin binding or trafficking to the cell surface. Biochemistry 2013, 52, 3310-3319. [CrossRef] [PubMed]

34. Ashton, L.; Brewster, V.L.; Correa, E.; Goodacre, R. Detection of glycosylation and iron-binding protein modifications using raman spectroscopy. Analyst 2017, 142, 808-814. [CrossRef] [PubMed]

35. Oyadomari, S.; Mori, M. Roles of chop/gadd153 in endoplasmic reticulum stress. Cell Death Differ. 2004, 11, 381-389. [CrossRef] [PubMed]

36. Iurlaro, R.; Munoz-Pinedo, C. Cell death induced by endoplasmic reticulum stress. FEBS J. 2016, 283, 2640-2652. [CrossRef] [PubMed]

37. Yang, Q.; Jian, J.; Katz, S.; Abramson, S.B.; Huang, X. 17beta-estradiol inhibits iron hormone hepcidin through an estrogen responsive element half-site. Endocrinology 2012, 153, 3170-3178. [CrossRef] [PubMed]

38. Shin, S.; Nam, J.H.; Hou, J.X.; Suh, J.S. A transient, microfluidic approach to the investigation of erythrocyte aggregation: The threshold shear-stress for erythrocyte disaggregation. Clin. Hemorheol. Microcirc. 2009, 42, 117-125. [PubMed]

39. Alexy, T.; Baskurt, O.K.; Nemeth, N.; Uyuklu, M.; Wenby, R.B.; Meiselman, H.J. Effect of lanthanides on red blood cell deformability and response to mechanical stress: Role of lanthanide ionic radius. Biorheology 2011, 48, 173-183. [PubMed] 